\title{
Field Research Report on Radioactive Cesium Contained in Persimmon Growing at Orchards of Fukushima Eight Years after the Nuclear Power Plant Accident
}

Kenji Kikuchi*

Frontier Research Center for Applied Atomic Sciences, Ibaraki University, Mito, Japan

\section{Introduction}

Test results on radioactive substances in Anpo-gaki [half dried persimmon] obtained in the year 2017 were posted on the Fukushima Prefecture website [1]. Parts of the experimentally processed persimmon on the collection date (purchase date) in September of this year exceeded 100 $\mathrm{Bq}$ per $\mathrm{kg}$, which is the standard value of the radioactivity concentration of foods set by the Ministry of Health, Labor and Welfare, Japan. As such, measures have been taken to avoid shipping of Anpo-gaki from that area as radioactive substances released into the environment from the explosion of the nuclear power plant in March 2011 remain in the environment.

In September 2017, environmental radiation monitoring was conducted at apple orchards in another district of Fukushima Prefecture. Radioactive cesium was detected in the soil of these orchards and in the barks of some of the trees but not in the edible parts of the apples. A hypothesis was formulated to understand the difference between the two findings, that is, "Radioactive cesium is not contained in the edible part of Anpo-gaki and the radioactive cesium present in the soil is also present in the experimentally processed products."

With the cooperation of Anpo-gaki farmers, field research was conducted in 2018 during the following stages: Before the trees bore the persimmon fruit; when the persimmons were not yet ripe; when the persimmons were ripe, and during Anpo-gaki production; at each stage, the amount of radioactive substances present was investigated.

\section{Research Methods}

Field research was conducted four times in 2018: On April 26, before the persimmon trees bore fruit; on August 29 , when the persimmons were not ripe; on November 6, when the persimmons were ripe, and on December 5, during Anpo-gaki production. We conducted the tests on three persimmon farms. The research parameters included the air dose rate, soil radioactivity concentration, persimmon radioactivity concentration, and environmental radiation levels at the respective production sites. A simple radioactivity measuring instrument, TechnoAP's TP100, was used to measure the radioactivity concentration. Samples were placed in U8 containers (content capacity $100 \mathrm{cc}$ ) under specific conditions using a $\mathrm{LaBr}_{3}$ scintillator, a measurement time of 20 or $40 \mathrm{~min}$, and a lower limit of quantification of $10 \mathrm{~Bq} / \mathrm{kg}$. Autoradiography was used to image the presence of radioactive substances in the soil and bark. The imager plate was a BAS-IP SR $2040 \mathrm{E}$ with a size of $20 \mathrm{~cm} \times 40 \mathrm{~cm}$; the imaging plate reader was a GE Healthcare's Typhoon FLA9500. An IWATSU SV-2000 with a silicon semiconductor scintillator was used to measure the air dose rate. A TGS-146, Aloka's GM pipe pollution meter was used. In the autoradiography imaging, irradiation boxes, each with a thickness of 5 to $10 \mathrm{~cm}$ were assembled with iron plates and lead blocks that were of thickness $5 \mathrm{~mm}$ to reduce the influence of external radiation. In addition, the imaging plate (IP) was shielded from $\beta$ rays $(210 \mathrm{~Pb})$ generated from the lead that was being used; this was achieved by sandwiching the box between two, $2 \mathrm{~mm}$ thick copper (oxygen-free copper) plates (see Figure 1). The imaging plate was wrapped in $0.012 \mathrm{~mm}$ thick aluminum foil, and the sample was placed between the upper and lower plates for use.

\section{Field Study}

\section{Before the trees bore the persimmon fruits}

We visited orchards in which the authorities were willing to cooperate with our measurements, and we explained the idea and purpose of our research. The timing and location of the research were agreed upon. Meanwhile, we obtained Anpo-gaki that was harvested and processed during the

*Corresponding author: Kenji Kikuchi, Frontier Research Center for Applied Atomic Sciences, Ibaraki University, Mito, Japan

Accepted: July 07, 2021

Published online: July 09, 2021

Citation: Kikuchi K (2021) Field Research Report on Radioactive Cesium Contained in Persimmon Growing at Orchards of Fukushima Eight Years after the Nuclear Power Plant Accident. J Soil Water Sci 5(2):193-196 
Citation: Kikuchi K (2021) Field Research Report on Radioactive Cesium Contained in Persimmon Growing at Orchards of Fukushima Eight Years after the Nuclear Power Plant Accident. J Soil Water Sci 5(2):193-196

previous year. Then, we experimentally measured the radioactivity concentration and found that the radioactive cesium was below the detection limit.

\section{When persimmons were not ripe}

Soil from persimmon orchards, moss from bark, and green persimmons were collected. Three research points (locations 1,2 , and 3) were used. Figure 2 shows the samples that were collected. Table 1 shows the measurement results of radiation concentration.

Numbers 1, 2, and 3 in Table 1 indicate the collection points. The air dose rates measured at a distance of $1 \mathrm{~m}$ from points 1,2 , and 3 were $1.26 \mu \mathrm{Sv} / \mathrm{h}, 1.29 \mu \mathrm{Sv} / \mathrm{h}$, and $1.11 \mu \mathrm{Sv} / \mathrm{h}$, respectively. In each case, moss on the bark that was at a height $30 \mathrm{~cm}$ above the ground was collected. The green persimmons were collected directly from trees. No radioactive cesium was detected in the green persimmons. However, cesium-137 was detected in the soil. Some amount of soil from U8 containers was placed in each plastic bag, and an autoradiography image was read. From the results, it was observed that the $\gamma$-ray sources adhering to all three soil samples were unevenly distributed; from the results of radioactivity measurement, it was found to be cesium-137 (see Figure 3).

\section{When the persimmons ripened}

Three research locations (locations 1, 2, and 3) were visited again, measured the air dose rate, and collected soil and ripe persimmons from the branches. The air dose rate at location 1 was $0.120 \mu \mathrm{Sv} / \mathrm{h}$ at a distance of $1 \mathrm{~m}$. The previous measurement value at the same location was $1.26 \mu \mathrm{Sv} / \mathrm{h}$, which is a tenth of the value measured this time. The air dose rate at location 2 was $0.121 \mu \mathrm{Sv} / \mathrm{h}$ at $1 \mathrm{~m}$. Compared to the previous measurement value of $1.29 \mu \mathrm{Sv} / \mathrm{h}$ at the

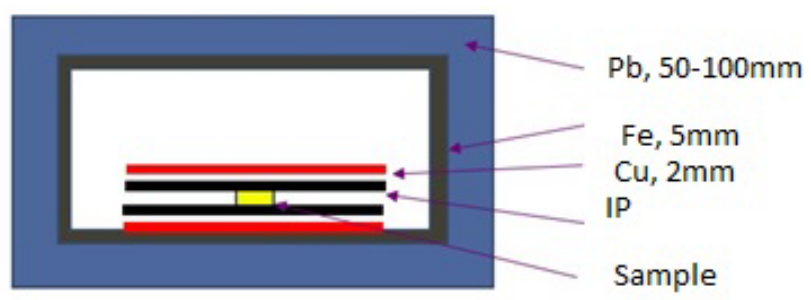

Figure 1: Illustration of shielding box for autoradiography to inspect particles including radioactive materials. Sample was sandwiched in between IPs and Cu plates.

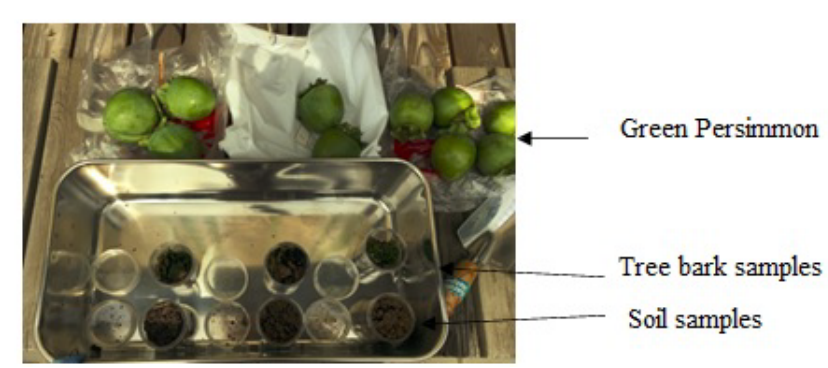

Figure 2: Samples of soil from persimmon orchards and moss from tree bark in the metallic container, and green persimmons.

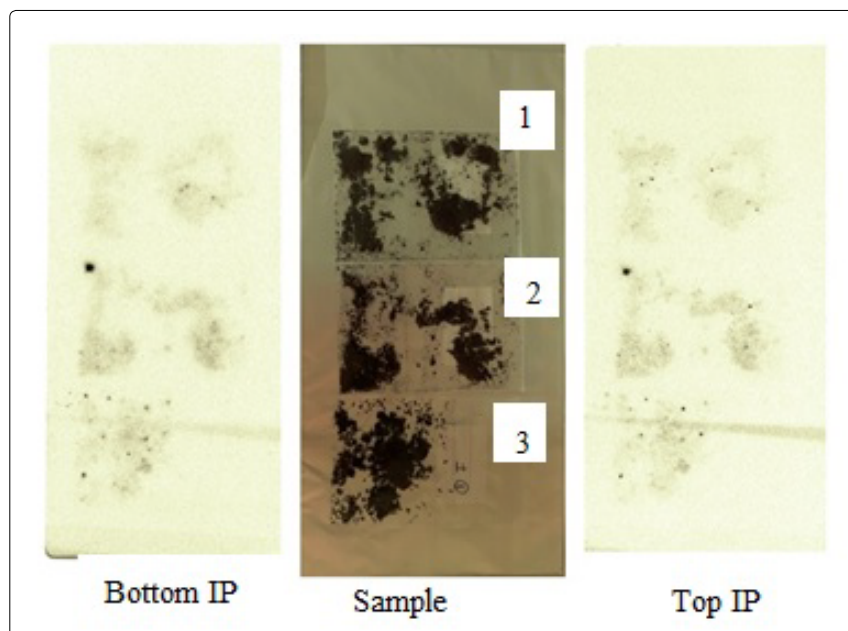

Figure 3: Autoradiography of the persimmon orchard soils at the time of persimmons were not ripe. Two images, bottom and top, show imaging plate put at the bottom and the top of the testing samples, respectively. The same dot images indicate the $y$-ray exposure from the soil samples. The $\gamma$-ray sources adhering to all three soil samples were unevenly distributed. It was found to be cesium-137 from the results of radioactivity measurement. The number 1, 2 and 3 indicates the number of sampling persimmon orchards location.

same location, this value was also reduced to $1 / 10^{\text {th }}$ of the previously measured value. At location 3 , the air dose rate was $1.19 \mu \mathrm{Sv} / \mathrm{h}$ at a distance of $1 \mathrm{~m}$, which was approximately equivalent to the previously measured rate of $1.11 \mu \mathrm{Sv} / \mathrm{h}$ at the same location. The reason why the air dose rate decreased at locations 1 and 2 was that there were traces of wild boar invading the persimmon farms and digging up the farm soil at depts of 10 to $20 \mathrm{~cm}$. Table 2 shows the measurement results of the radiation concentration of soil and persimmons. Radioactive cesium remained in the soil, but it was found that the content was below the detection limit for persimmons. Compared to the value for the unripe, green persimmons, the radioactivity concentration contained in the soil decreased too approximately $80-90 \%$; that is, the decrease in the air dose rate was due to the shielding effect of the soil by conducting deep ploughing. Figure 4 shows the autoradiographic image of the soil collected when the persimmons were ripe. Black spots pointing to the radiation source were marked on the upper and lower two imaging plates.

\section{During Anpo-gaki production}

The research was conducted at production sites where persimmons that were harvested were made into Anpogaki. There was a place to peel persimmons, a closed indoor drying place, and an open-air drying place. At the site to peel persimmons, the waste on the floor near the entrance was collected and placed in a U8 container, and the peeled skin was also collected in another U8 container. At the open-air drying area, waste on the floor was collected in a plastic bag.

In addition, we visited an unused building that was suitable for use as a drying area. As a high dose remained along the drainage, we used a GM-type pollution meter to measure the cesium content. The results indicated that amounts of 700 $\mathrm{cpm}$ at $1 \mathrm{~cm}$ and $150 \mathrm{cpm}$ at $1 \mathrm{~cm}$ on the outside mountain 
Citation: Kikuchi K (2021) Field Research Report on Radioactive Cesium Contained in Persimmon Growing at Orchards of Fukushima Eight Years after the Nuclear Power Plant Accident. J Soil Water Sci 5(2):193-196

Table 1: Measurement results of radiocesium concentration at the time of persimmons were not ripe.

\begin{tabular}{|c|c|c|c|c|}
\hline Location point & Sample & Net weight, & $\begin{array}{c}\text { Concentration of Cs-137, } \\
\mathbf{B q} / \mathbf{k g}\end{array}$ & $\begin{array}{c}\text { Concentration of Cs-134, } \\
\mathbf{B q} / \mathbf{k g}\end{array}$ \\
\hline 1 & Persimmon & 95 & ND & ND \\
\hline 2 & Persimmon & 100 & ND & ND \\
\hline 3 & Persimmon & 90 & $473.9(85.4)$ & ND \\
\hline 1 & Soil & 67 & $2429.7(177.6)$ & ND \\
\hline 2 & Soil & 41 & $1001.0(174.5)$ & ND \\
\hline 3 & Soil & 33 & ND & ND \\
\hline 1 & Moss from tree & 4 & $661.9(205.1)$ & ND \\
\hline 2 & Moss from tree & 26 & $1881.5(425.8)$ & ND \\
\hline 3 & Moss from tree & 13 & ND \\
\hline
\end{tabular}

Suffix 1,2 and 3 indicates the number of sampling persimmon orchards. ND means the value less than $10 \mathrm{~Bq} / \mathrm{kg}$.

Table 2: Measurement results of radiocesium concentration at the time of persimmons were ripe.

\begin{tabular}{|c|c|c|c|c|}
\hline Location point & Sample & Net weight, $\mathbf{g}$ & $\begin{array}{c}\text { Concentration of Cs-137, } \\
\mathbf{B q} / \mathbf{k g}\end{array}$ & $\begin{array}{c}\text { Concentration of Cs-134, } \\
\mathbf{B q} / \mathbf{k g}\end{array}$ \\
\hline 1 & Persimmon & 90 & ND & ND \\
\hline 2 & Persimmon & 92 & ND & ND \\
\hline 3 & Persimmon & 94 & ND & ND \\
\hline 1 & Soil & 65 & $366.3(85.0)$ & ND \\
\hline 2 & Soil & 61 & $1904.6(124.8)$ & $258.2(62.4)$ \\
\hline 3 & Soil & 55 & $759.8(108.8)$ & ND \\
\hline
\end{tabular}

Suffix 1, 2 and 3 indicates the number of sampling persimmon orchards. ND means the value less than $10 \mathrm{~Bq} / \mathrm{kg}$.

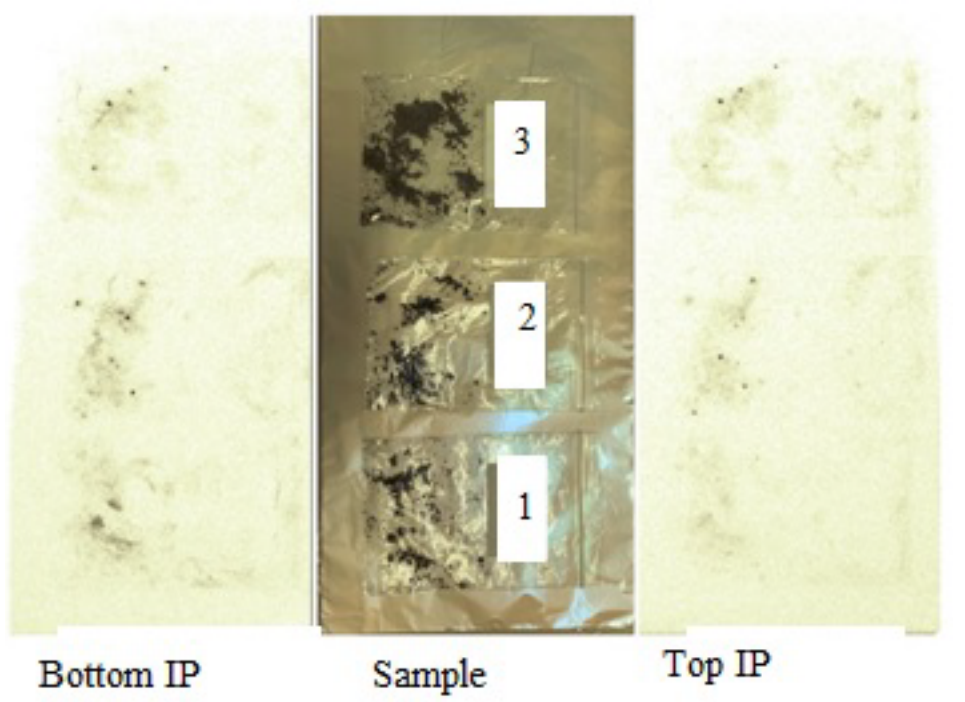

Figure 4: Autoradiography of the persimmon orchard soils at the time of persimmons were ripe. Two images show imaging plate put at the bottom and the top of the testing samples, respectively using the same technique with the Figure 3 results. The $\gamma$-ray sources adhering to all three soil samples were unevenly distributed. It was found to be cesium-137 from the results of radioactivity measurement. Suffix 1, 2 and 3 indicates the number of sampling persimmon orchards.

surface were present. Therefore, decontamination should be considered in this area.

As the amount of waste collected was extremely small, autoradiography was directly imaged without measuring the radioactivity level. Double-sided adhesive carbon tape was attached to the aluminum foil, and the collected waste was scattered on it to fix the measurement location. Furthermore, it was covered with plastic cling film to prevent the adhesive tape from sticking to the imaging plate.

Figure 5 shows the results of the autoradiography of the floor dust in the sealed indoor drying room (top), of the floor dust in the outside air-release drying room (middle), and of the ground soil in the persimmon peeling indoor room (bottom). No radiation source was found in the floor dust of the outside 


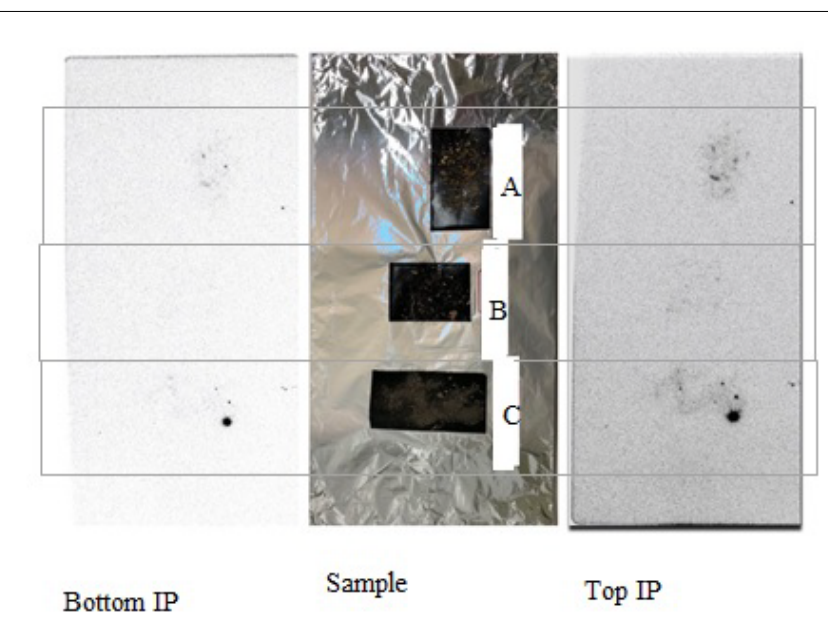

Figure 5: Autoradiography of the floor dust in the sealed indoor drying room $(A)$, of the floor dust in the outside air-release drying room (B), and of the ground soil in the persimmon peeling indoor room (C). No radiation source was found in the floor dust of the outside air- release drying room. The radioactivity sources, black dots, were found on the top and bottom views.

air-release drying room. The radioactivity sources, black dots, were found on the top and bottom views.

The radioactivity level of the floor waste in the floor dust in the persimmon peeling indoor room was measured, and cesium-137 was detected at a level of $1783 \pm 422.9 \mathrm{~Bq} /$ $\mathrm{kg}$. Peeled persimmon skin did not reveal the presence of radioactive cesium.

\section{Summary}

With the cooperation of the authorities of Anpo-gaki orchards, we conducted field research at various stages: Before persimmon fruit ripened, when persimmons were not ripe, when persimmons were ripe, and during Anpo-gaki production. The persimmon fruit did not contain radioactive cesium (below the detection limit) and radioactive cesium was detected in the soil where the persimmon trees were planted. At the Anpo-gaki production sites, radioactive cesium was detected in the waste material present on the floor of areas that were used to peel persimmons and in closed indoor drying areas.
While conducting the field research in 2018, the inspection results were reported that experimentally processed persimmons in the Fukushima Prefecture yielded 6 samples containing radioactive cesium above the standard value [2].

The Fukushima Prefecture website also reports on the inspection of radioactive substances in processed foods. Radioactive cesium was detected in some dried fruit samples, which were requested to be removed from processing by the prefecture [1]. In the above two reports, the details are unknown because the locations where radioactive cesium was detected in the test samples were not described.

From the results of this study, it was found that no radioactive cesium was detected in persimmon fruits. The initial hypothesis stating that "radioactive cesium is not contained in the edible part of Anpo-gaki and radioactive cesium present in the soil is present in the experimentally processed products" has therefore, not been proven.

\section{Recommendations}

- In the production of Anpo-gaki, the establishment of a boundary line between the floor of the processing plant and the area outside should be considered so that radioactive cesium is not brought into the processing plant.

- When harvesting persimmons, the harvested persimmons are placed in plastic containers. During this process, measures should be taken as radioactive cesium is attached to the soil of the persimmon farms.

- For samples that failed the test processing, effective countermeasures may be found by conducting additional research that follows the tests that separately inspect the inside of persimmons, the surface of the persimmon, and packaging materials.

\section{Acknowledgements}

The study was supported partly by Nuclear Regulatory Authority, and JSPS KAKENHI Grant Number JP18K19867.

\section{References}

1. http://www.pref.fukushima.lg.jp/site/portal-english/

2. (2018) Seikei Tohoku magazine, 42-43.

DOI: $10.36959 / 624 / 444$ 